\title{
Missing Heroes of Pancreatic Surgery
}

\author{
Dezső Kelemen \\ Department of Surgery, Clinical Centre, University of Pécs, Pécs, Hungary
}

\section{Dear Editors,}

The current issue of Digestive Surgery deals with the past, present and future of pancreatic surgery [1]. All authors are excellent representatives of their field and I took a delight in reading the articles. However, I miss 2 persons from this group, namely Hans G. Beger and Markus W. Büchler. Professor Hans G. Beger - a living legend - is now professor emeritus, and he was head and chairman of the Department of General Surgery in Ulm, Germany, between 1982 and 2001. He was the president of national and international societies in the field of gastrointestinal surgery. He has received numerous international awards and prizes for his work. Professor Beger has written 24 books and more than 740 origi- nal papers. Due to his worldwide reputation, at that time, Ulm was a reference center in the field of pancreatic surgery. As the most remarkable result, he has developed a fundamentally novel surgical method, namely the duodenum-preserving pancreatic head resection, which is a procedure now used all over the world, that has become one of the standard operations for the surgical treatment of chronic pancreatitis with inflammatory head enlargement [2]. From this principal operation, several modifications can be derived. His best former co-worker and follower is Professor Markus W. Büchler. He has been the head and chairman of the Department of General, Visceral and Transplantation Surgery in Heidelberg since 2001. In the same year, the European Pancreas Centre was established at Heidelberg University Hospital. He has gained numerous honorary professorships and also memberships, scientific appointments and journal affiliations. His clinical and laboratory studies in pancreatology have resulted in over 2,200 publications. Beside the huge and successful activity in pancreatic surgery, he has developed the so-called Bern modification of the Beger procedure [3]. As Ulm was previously, now Heidelberg is a reference center of pancreatic surgery in Europe. The survey of the history of pancreatic surgery would have been perfect with the paper of the above-mentioned notabilities.

\section{References} and future. Dig Surg 2016;33:257-258.

2 Beger HG, Schlosser W, Friess HM, Büchler MW: Duodenum-preserving head resection in chronic pancreatitis changes the natural course of the disease: a single-center 26-year experience. Ann Surg 1999;230:512-529; discussion 519-523.

3 Gloor B, Friess H, Uhl W, Büchler MW: A modified technique of the Beger and Frey procedure in patients with chronic pancreatitis. Dig Surg 2001;18:21-25.

\section{KARGER}

E-Mail karger@karger.com www.karger.com/dsu (c) 2016 S. Karger AG, Base

0253-4886/16/0341-0086\$39.50/0
Professor Dezső Kelemen, MD, PhD

Department of Surgery, Clinical Centre, University of Pécs Leader of Pancreatic Surgical Profile of Pécs University Hospital Ifjúság u. 13, HU-7624 Pécs (Hungary)

E-Mail kelemende@gmail.com 